I never really worked on ceramics-they are much too difficult for me, with more than one type of atom and structures that are not always fcc. However, the first comment people usually make upon entering my office is about my ceramics-that is, my collection of mugs. It started in 1975, when I spent a year at Cornell. After giving a seminar to the Materials Science \& Engineering Department, I was presented with the Cornell "invited speaker's mug." I now have about a hundred mugs lining my bookshelves, every one of which tells a story.

Most of the mugs are very ordinary, viewed as structural or aesthetic objects. You would not use the adjectives "fine," "functional," or "advanced" to qualify them as ceramics-"cheap" would be more likely. However, many of them do act as reminders of the depth, variety, and ubiq uity of materials science. Of local interest is my Sunlight Soap mug. I pass the delightful village of Port Sunlight every evening on my way home. The whole village was built by an early Lord Lever as a model village and, as well as the wonderful Lady Lever Art Gallery, it is the home of the Unilever Research Laboratory. Unilever still made Sunlight Soap until a couple of years ago, but now the scientists I know there are engaged in sophisticated studies of the interaction between keratin and detergents and in the absorption of photons by nanoparticulate components of sunscreens. Big business and big science.

\section{A Mug's Game}

Another particular favorite is one of those corny mugs that changes color when coffee is added. Thermochromic inks are undoubtedly old hat, but it is amazingly difficult to find out which system was used. You can look up leucodyes and liquid crystals, but it is very difficult to reverse-engineer a thermochromic material locked in a domestic artifact-and just try contacting the manufacturer of a mug: You will not find anyone who knows!

Another of my exhibits features a picture

of my own canal narrowboat, presented

as a parting gift by an upwardly mobile ex-secretary. This opens avenues of thought relating to printing, now making a huge comeback with the development of inkjet deposition for a thousand new materials purposes. The boat itself, made of steel, serves as a constant reminder of the issue of cor-

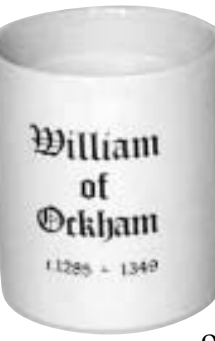
rosion and the inadequacy of good, cheap, easy-to-apply protective coatings.

I also have a couple of historical favorites: Robert

Hooke, the multitalented scientist and engineer of his day, died 300 years ago having come up with the compound microscope, the iris diaphragm, and the universal joint (and a lot of other things). Hooke's Law was first published as an anagram (ceiiinosssttuv), to keep it from being understood by others-not a good example of our modern open scientific method! In Latin, this comes out as ut tensio sic vis, or (more or less) "as the force, so the displacement." This makes a good mug from the Isle of Wight, where Hooke was born.

An even better one, because of its absolutely eternal relevance, features Occam's razor. This was propounded in the 14th century by William of Ockham as frustra fit per plura quod potest fieri per pauciora. This roughly translates as "It is vain to do with more what can be done with fewer"; or, if there is a simple explanation and a more complex one-choose the simpler. I have used Occam's razor many times, but why do I have it on a mug? It is available in my mother's local parish church-in Ockham, England!

One mug is particularly special and prompts me not to take anything for granted. It is not ceramic, but pewter. This was a gift from the Institution of Engineers in Malaysia and was, of course, made in Selangor. It is inscribed speciallya huge advantage that metals have over ceramics. However, coffee does not taste too good out of it!

The sources of these, along with all of the other mugs, have one thing in common: I learned something there and I remember it largely because of the mug. Oh-yes, I do have an MRS mug. Peter GoOdHew 